\title{
The Public Function in The Regulation of Food: Ethics and Prevention
}

\author{
Maria Teresa Sotelo M* \\ President Fundacion Prevencion a la Violencia Infantil, Mexico
}

*Corresponding author: Maria Teresa Sotelo M, President Fundacion Prevencion a la Violencia Infantil, Mexico.

Received Date: August 01, 2018

Published Date: August 24, 2018

\begin{abstract}
The restriction of transgenic components of high toxicity, the use of contaminated irrigation water with poisonous pesticides, as well the indiscriminate comestible animals fed with synthetic hormones, should be prohibited and sanctioned by the sanitary authorities under a World Health Council of Public Health, regulated by a group of international observers, not financed by the private food industry, either by transnational linked to the edible industry, with authority to sanction irregularities and compel government media campaign disclosure to the population on consumption risks.
\end{abstract}

Keywords: Transgenic; Food; Toxicity; Sanitary; Regulation; Illness

\section{Introduction}

Diverse medical research acknowledges food a broad impact on the body and contributes to the individual correct or incorrect metabolic, endocrine and neurological functioning whose significant repercussions of specific contaminated substances and foodstuffs, are reflected in public expenditure, assigned to the treatment of various diseases and disabilities, as well as in the advance of violent behavior.

Thousands of plenty insecticides, are utilized every year on crops, contaminating soil, water, air and food. In 2014, 78,926 tons of pesticides were marketed in Spain alone, 24\% more than in 2012. A single piece of fruit or vegetable could contain several different pesticides and a plate of salad or fruit cocktail, dozens of them. Transgenic foods have contributed to the proliferation of diseases, allergies and poisonings, due to residues of some lethal Agrochemicals and pesticides in comestibles, despite the debates and studies that counteract or contradict toxicity in the human body, such as the report presented by the National Academy of Sciences of the United States, published in May 2016 "Genetically Manipulated Crops: Experiences and Perspectives". Which summarizes in 420 pages, the work of 20 independent scientists, who listened to 80 presentations, reviewed thousands of scientific studies having received more than 700 comments from organizations and the general public, whose debates offered in conclusion, not having found higher incidence of cancer, obesity, diabetes, autism, kidney disease and others, denying even having found the transfer of genetic material through breast milk or in food. Other recent medical research denotes, that glyphosate, [active ingredient of Monsanto's Roundup herbicide] used in big quantities in transgenic or genetically altered crops, can cause a wide range of diseases, including brain disorders. Swanson [1] offers data on prevalence and incidence, with their respective correlation between diseases of the organs and the increase of GM, genetically modified organisms (GMOs) in the food supply, together with the increase in the applications of herbicides based on glyphosate. Mercola [2] on his website, divulges a test he carried out to analyze the amount of pesticides that only the running tap water could contain. The results revealed more than 50 different chemicals in the water, [from his home in Miami] which varied between 3 and 11 parts per trillion, including atacor, atrazine, lindane, chlordane, endrin, heptachlor, epoxide, simazine, toxifin, 2,4-D, dalapron, dinazeb, ntachlorophenol, carbofuran and oxymel.

Several regulatory reports have suggested the role of substances with similar effects to anabolic steroid hormones in the animal bovine production, which are injected into animals to increase muscle power and growth to make the appearance of freshness and quality, including Clenbuterol. Hormonal contaminants, is the ability of some chemicals to interfere with the hormonal or endocrine system, causing adverse effects in the body. Endocrine disruptors interfere with the natural action of hormones and can 
alter the physiology of an individual, from fetal development, to adulthood, leading to malformations, pathologies or irreversible diseases. Some EDCs can produce epigenetic changes, that is, modifications in the expression of genes that can be transmitted to descendants genetically modified.

Michael Hansen [3], advisor to the United States Consumers Union, adverts that large part of the industrial milk production in the United States, Mexico, and other Latin American countries, uses a transgenic bovine growth hormone called RBGH, Somato-Tropina Bovina or BST [for its acronym in English]. Hansen remarks, this is the hormone mostly injected into cows, to make them up to produce twice as much milk, with negative effects on the health of livestock, warning about fatal consequences for those who consume these dairy products, due this transgenic hormone causes IGF- 1 (insulinlike growth factor type 1) associated with the development of breast, prostate and colon cancer.

The World Health Organization, reports, that obesity has almost tripled worldwide, due to consume high-calorie ingredients as eating habits in the population Since 1975. Other studies attribute to genetically modified foods and the relationship with fast food such as hamburgers, pizzas, hot dogs, nachos, among others. The global fast food market grows rapidly worldwide, notwithstanding it is practically monopolized by the United States, with figures that reached 63,799 million euros invested in junk and rapid food in 2013. According to a study conducted by the EAE Business School, all countries have shown a remarkable impact in the consumption of snacks since 2007 .

According to the World Health Organization, in 2016, more than 1900 million adults aged 18 or older, were obese. Also, more than 340 million children and adolescents ( 5 to 19 years old) were overweight or obese.

Tufts University conducted a study in 42 restaurants, both fast food and menu of the day. The intention was to compare the caloric content of the aliments, and the result showed $40 \%$ of the food contained $10 \mathrm{kcal}$ additional per serving, then those indicated on the package or menu. The impact of the consumption of certain foods, is not only limited to the health or illness by its content, but by the metabolic process that the organism presents to certain substances that alter the endocrine function, being a precursor of violent behavior. Studies carried out at the University of Helsinki, exposes that aggressive people have a lower tolerance to glucose, and suffer reactive hypoglycemia after consumption of sugars, likewise have low levels of serotonin in the brain. Both alterations are enhanced by the consumption of alcoholic beverages. Hypoglycemia or low blood glucose can occur as a reaction after consumption products rich in refined sugars, and poor in fiber, such as sweets, cakes, sweets and alcohol intake. Fluctuations in the blood glucose level favor aggressive behavior.

Dr. Steed conducted an Ohio conditional study on the effect of diets on the behavior of convicts for conditional rape. $56 \%$ of the offenders who had relapsed the jail, their consumption of sugar, junk food and canned goods were very high during their probation. However, some ex-convicts who had maintained a balance nutrition only $8 \%$ had incurred in criminal acts.
The publication of the study "Topographic mapping of brain electrical activity in children with food-induced attention deficit hyperkinetic disorder", presents the conclusions derived from a topographic mapping of brain electrical activity to 15 children with hyperactivity disorder, and attention deficit. The results reported that during the consumption of stimulant foods, a significant increase in beta1 activity was identified in the frontotemporal areas of the brain, showing an association between cerebral electrical activity, and the intake of stimulating foods. During the induced test, sugar, dyes, wheat and banana were used.

\section{Method}

Collected data were analyzed from various medical scientific publications throughout cross-statistical reports on dietary habits and associated diseases. It was identified through a descriptive medical publication review, toxic substances with methods, and cultivation procedures. As well the authorization procedures in the food manufacture. The records obtained ranged between 86 and $93 \%$ of matches, by means of a comparison between the primary studies and the results.

\section{Analysis}

Difficult to know the scope of the study and the veracity of the published findings of the Committee on Genetically Engineered Crops: Past Experience and Future Prospects, particularly in poorly analyzed situations or hidden components in agricultural practice. It is no secret that the chemical industry manipulates data to avoid risks and alters the legal limits of the reported toxin in the formula.

Part of the manipulation of security limits involves suppressing data, which generates alarm signals. As a general rule, the regulators take as a reference to validate the product, the studies presented by the companies themselves, and most are confidential, making it impossible for the population and other researchers to access the real composition. The process is called "regulatory capture"; which is the way the industry actually captures the regulators, this strategic practice is used by the toxic industries of tobacco, asbestos, lead and pesticides worldwide. The position of the study does not justify what reality presents when studying the statistics of diseases by crossing data with the food eating routines of the population. It is not a coincidence, the high levels of morbid obesity in the North American population, and their consumption habits, being this nation the one that presents biggest fast food expenditure in the world, which amounts raised to 55 thousand 524 million euros. According to the EAE [Strategic environmental evaluation. 2014] [4-13].

The ingredients of the so-called fast food, are practically altered by hormones to achieve greater harvesting in production, a process which is attributed to the proliferation of morbid obesity in the citizens and the endless chain of millions of people who suffer diverse derived sicknesses, discapacity and death in the US and other countries, for the indiscriminate consumption of junk food, pizzas, sodas, hamburgers and processed comestibles in general. Here the studies that minimize or deny the risks, lose credibility before the blunt and revealing the truth, palpable in the rates of mortality and chronic diseases derived. 
Several scientific studies have repeatedly warned about the impact of food on violent behavior, pointing accurately to substances such as sugar, alcoholic beverages, artificial additives and diets lacking essential fatty acids, vitamins and minerals such as iron, which promote hyperactivity and Aggression, notwithstanding medical warnings, remains a public health problem ignored by most people. This means that the authorities responsible for the prevention of health, do not undertake public campaigns warning the population about their consumption and intake. Undoubtedly it is not just a matter of healthy eating habits to modify a behavior, but there is a clear relationship between the trigger substances in the organism that generate violent impulses.

Who warns us against the additives that cause health disorders? Who sanctions the use of toxic agrochemicals in the process of crop production? Who watches over a defenseless population? The authorities very so often assume positions of submission, and do not exert jurisdiction in front of tempting offers from irresponsible labs processing food ignoring the physical, economic and psychosocial population impact that implies feeding people with hormones, larvae, and toxicity. On the one hand, the great petty economic interests, along their group of paid scientists. On the other, the authorities who are silent so as not buying problems, lending themselves, not to prohibit ingredients and bad practices, relying on regulatory insufficiency. Officials that choose not to move deep waters, protecting a poorly paid salary and compromising the health of the people.

A clear example of the above, In September 2008, the Sanlu group from China, drew international attention about their brand baby milk formula, whose advertising boasted the high protein content of its product. When at least six babies died, it was discovered that the milk was contaminated with melamine, a powdered substance used for the manufacture of plastics and cement. Had it not been for the coincidence of the deaths as a result of the consumption of the same milk, its production methods that included this substance could never have been known. Given the overwhelming scientific evidence of the potential harm to the health of certain substances contained in some foods, why should not the official institutions that are obliged to watch over health do not undertake massive campaigns of cross communication to alert people, besides modifying some useless regulatory rules? As a simplistic example, without rhetoric and compromises, we could imagine what would be the society response, if a media campaign were launched to warn parents the risk of their children could be affected with hyperactivity, obesity and violent behavior, by the excessive intake of products with sugar, wheat, junk food, soft drinks and alcohol? The answer is totally predictable, there would be a rampant decrease in the sale of sweets, cakes, pizzas, soft drinks and alcoholic beverages. The question is why not the government and health authorities do a media campaign? If the elimination of a product is able to improve the behavior of an aggressive person? Maybe the answer leaves many questions, corruption? Lack of common sense? Ignorance? Dark interests? Excessive governmental locks for institutional autonomy regarding mass prevention communication? The institutional care of physical and mental health should be necessarily linked to nutrition, as a mechanism of controlled intervention, promoting the selection of specific counseling methods with control strategies. The World Health Organization on its website, allude the proliferation of diseases due to lack of support policies in sectors such as health; Agriculture; transport; urban planning; environment; and processing, distribution, food marketing, and education. The restriction of transgenic components of high toxicity, the use of irrigation with water contaminated by pesticides, the indiscriminate feeding of livestock and birds with hormones, should be clearly prohibited and sanctioned by the sanitary authorities under a World Health Council of public order, regulated by a group of international observers, not financed by the private food industry, nor by transnational linked to the food industry. A council with moral and legal authority to sanction irregularities, with various organization representatives, such as the World Health Organization (WHO). World Trade Organization (WTO); Pan American Health Organization PAHO; United Nations Organization for Agriculture and Food FAO, UNICEF, among others, whose participation should not be limited to the governmental, institutional obligation to the design and application of counseling programs and nutritional protocols, but in the use of theories and models of change to achieve impact on health and positive human behavior.

\section{Conclusion}

The validity of studies that minimize the risks and deny any relation between illnesses due to the intake of transgenic foods, and the hormone injection of cattle and birds, lose credibility due to the evidence of the statistics of the increase in obesity and in multiple diseases derived from harmful habits in the rapid and junk food intake by the population. It is suggested the creation of a World Health Council, regulated by a group of international observers with moral and legal authority to sanction irregularities, in the production, preparation and distribution of food and substances that threaten health. The governments should assume the diffusion of mass communication campaigns, to create in the population habits of healthy eating habits, warning about the excessive consumption of fast and junk food, as precursors of obesity and associated diseases. In like manner, spreading out clearly the risks of harmful comestibles in the inhabitant's conduct, by publicly admitting that based on scientific evidences, substances such as sugar, wheat, and alcoholic beverages, among others, trigger insulin spikes, that contribute to violent impulses. Mass media permanent campaigns warning population on their intake risks consumption, should be made public as governmental regulation function.

\section{References}

1. Nancy L Swanson, Andre Leu, Jon Abrahamson, Bradley Wallet (2014) Genetically engineered crops, glyphosate and the deterioration of health in the United States of America. Journal of Organic Systems 9(2): 6-37.

2. Mercola. What's Causing the Rise in ADHD?

3. Andreas Kortenkamp, Olwenn Martin, Michael Faust, Richard Evans, Rebecca Mc Kinlay, et al (2011) State of The Art Assessment of Endocrine Disrupters, Final Report. 7-135.

4. Bergman A, Jerrold J Heindel, Susan Jobling, Karen A Kidd, R Thomas Zoeller (2012) State of the science of endocrine disrupting chemicals. 1-29. 
5. Committee on Genetically Engineered Crops: Past Experience and Future Prospects, National Academies of Sciences, Engineering Medicine, Board on Agriculture and Natural Resources, Division of earth and Life Studies (2016) Genetically Engineered Crops: Experiences and Prospects. Washington, National Academies Press, 1-384.

6. Pat Thomas (2003) La comida basura aumenta la violencia social. Azúcaramargo.

7. Uhlig T, Merkenschlager A, Brandmaier R, Egger J (1997) Topographic mapping of brain electrical activity in children with food-induced attention deficit hyperkinetic disorder. EUR J Pediatr 156(7): 557-561.

8. David Benton (2007) The Impact of Diet on Anti-Social, Violent and Criminal Behaviour. 31(5): 752-774.
9. Huxtable, Ryan (1982) Amino Acids your health defenders. Prevention Magazine. 56-62.

10. Organización Mundial de la Salud. Obesidad y sobrepeso.

11. Atroshi F, Sandholm M (1982) Red blood cell glutiathione as a marker of milk production in finn sheep. Research in veterinary Science, 33(2): 256-259.

12. Nassett, Edmund Sigurd. Food and You. New York: Barnes and Noble, Inc, 1958.

13. Garcia Kistine Romano Dolores, Directo a tus hormonas: guía de alimentos disruptores Residuos de plaguicidas con capacidad de alterar el sistema endocrino en los alimentos españoles. 4-20. 